\title{
Blocos de concreto para construção modular de silos cilíndricos
}

\author{
José W. B. do Nascimento ${ }^{1}$, Kuelson R. D. Maciel' ${ }^{2}$, Valneide R. da Silva ${ }^{1}$, Fernanda F. de M. Lopes ${ }^{3}$ \& José P. Lopes Neto ${ }^{4}$
}

\begin{abstract}
RESUMO
Estima-se que, atualmente, $25 \%$ da produção de grãos produzidos no Brasil são perdidos nas fases de colheita e pós-colheita, mas esta realidade pode ser minimizada caso o País estimule a estocagem da produção. Com o intuito de promover, de forma economicamente viável, a armazenagem da produção nas fazendas, objetivou-se estudar blocos de concreto para utilizá-los na construção de silos cilíndricos de alvenaria. Desenvolveram-se blocos com geometria especial, moldados nos traços (cimento: areia) de 1:3, 1:4 e 1:6, os quais foram analisados pelos testes de absorção de água, resistência á compressão e ao cisalhamento, submetidos a dois tipos de cura: natural e submersa. Dentre os traços estudados os que atingiram a resistência á compressão exigida pela ABNT 7173, foram os de 1:3 e 1:4 e, como para a resistência á tração não há uma norma específica foi desenvolvida uma metodologia para simular 0 esforço de tração a que as paredes dos silos cilíndricos são submetidas. $0 \mathrm{~s}$ blocos moldados com os traços 1:3 e 1:4 atingiram resistência superior à necessária para um silo com 4,0 $\mathrm{m}$ de altura e relação altura-diâmetro igual a 1.
\end{abstract}

Palavras-chave: técnica construtiva, resistência, armazenamento de grãos

\section{Concrete blocks for the modular construction of circular silos}

\begin{abstract}
At present it is estimated that $25 \%$ of the production of grains produced in Brazil is lost during harvest and post harvest phases but this can be reduced, in case, the country stimulates the storage of production. With the intention of promoting the storage of production in an economically viavel form, this work had the objective of studying the use of concrete blocks in the construction of circular silos. A block was developed with special geometry, moulded with mortar of 1:3, 1:4 and 1:6 (cement: sand), which was analyzed by water absorption, compression and shear strength tests and submitted to two types of cure: natural and submerged. Among the studied mixtures which achieved the compression resistance required by ABNT 7173 were 1:3 and 1:4. Since there is no specific norm for tension strength, a methodology was developed to simulate the tension force to which the walls of the circular silos are submitted; the blocks molded with 1:3 and 1:4 mortars achieved strength necessary for a silo with height of $4.0 \mathrm{~m}$ and height/diameter ratio equal to 1 .
\end{abstract}

Key words: constructive technique, strength, storage of grains

1 UFCG/UAEA. Av. A prígio Veloso, 882. Bodocongó. Campina Grande - PB, CEP 58.429-190, Fone (83) 3310-1482.

E-mail:wallace@deag.ufcg.edu.br,rval707@yahoo.com.br

2 ILES/ULBRA- Porto Velho. Email: kuelson@gmail.com

3 UFCG/UAEP . Email: fndmelo@yahoo.com.br

${ }^{4}$ UFCG/UATA. E-mail: Iopesneto@gmail.com 


\section{INTRODUÇÃO}

A produção agrícola brasileira tem apresentado, nos últimos anos, elevado crescimento aliado não apenas a uma vasta extensão de terras produtivas cultivadas mas também a um nível avançado de tecnificação de suas lavouras. O Brasil se destaca como um dos maiores produtores e exportadores de grãos porém esta elevada produção não é o suficiente para mantê-lo com boa margem de competitividade no mercado agrícola internacional. Sabe-se que uns dos principais obstáculos na produção graneleira é o desperdício ocasionado, em geral, pelas perdas pós-colheita, principalmente no que se refere à armazenagem de grãos. Uma solução prática para a redução dessas perdas seria a implantação de silos corretamente projetados e construídos de forma a atender às necessidades do mercado agrícola.

De acordo com Diniz \& Nascimento (2006), uma unidade armazenadora, tecnicamente projetada e convenientemente localizada, constitui uma das alternativas para aumentar os retornos econômicos dos sistemas produtivos de grãos além de propiciar a comercialização da produção em melhores épocas evitando o período da queda de preço na época de colheita.

Os silos podem ser construídos de diversos materiais, como madeira, argamassa armada, concreto e aço. Safarian \& Harris (1985) ressaltam que silos de concreto possuem as vantagens de apresentarem boa resistência ao fogo, serem de fácil montagem, desmontagem e transporte, de que eventuais danos à sua estrutura possam ser facilmente reparados, além do fato de que estruturas de reforço são usualmente instaladas externamente ao silo facilitando, assim, possíveis manutenções. Em contrapartida, tais estruturas estão sujeitas a infiltrações que depreciam sua aparência, pois além de deteriorar os blocos de concreto, requerem fundações mais resistentes e manutenções internas a cada 5 a 10 anos.

A confecção de silos em blocos de concreto não implica apenas na armazenagem propriamente dita, mas um conjunto estrutural capaz de resistir às pressões impostas pelo produto ensilado, aliado às interferências internas. Ao conjunto estrutural se denomina alvenaria, caracterizada pela disposição em painéis unidos por meio de argamassa e encaixe, formando um conjunto coeso e rígido para construção (Silva et al., 2005).

Os blocos de concreto para alvenaria podem ser definidos, de forma geral, como elementos pré-moldados de concreto, a partir da mistura adequada entre agregados graúdos e miúdos, cimento e água. Uma conceituação mais objetiva define o bloco de concreto como a unidade de alvenaria constituída pela mistura homogênea adequadamente proporcionada de material cimentante, areia e água, conformada através da compactação manual e com dimensões superiores a 250 x 120 x 55 $\mathrm{mm}$, respectivamente comprimento $\mathrm{x}$ largura $\mathrm{x}$ altura (Sousa, 2001).

Os blocos de concreto são utilizados na produção das alvenarias permitindo o emprego de técnica de coordenação modular e contribuindo para a construção mais racional. Entretanto, para que os blocos efetivamente contribuam para a racionalização da produção das alvenarias é necessário asse- gurar a conformidade em relação as especificações estabelecidas pelas normas técnicas pertinentes (Lordsleem Júnior et al.,2008). A vulnerabilidade do concreto diante de condições de agressividade do meio é um fator bastante preocupante na avaliação da vida útil das estruturas dessa origem, pois uma durabilidade inadequada pode manifestar sérias complicações, comprometendo a utilidade das mesmas (Vieira et. al. 2004)

Um dos grandes entraves para a utilização de agregados reciclados de resíduos de construção e demolição refere-se a sua grande heterogeneidade. Por outro lado, para os resíduos de concreto de fabricas de pré moldados, o processo de beneficiamento pode ser considerado simplificado, uma vez que são constituídos basicamente de rejeitos de concreto provenientes de elementos rejeitados pelo controle de qualidade, sobras de concreto fresco e unidades danificadas durante o transporte e estocagem (Buttler \& Corrêa., 2006)

Praticamente, todos os tipos de cimento podem ser utilizados na produção de blocos de concreto; entretanto, na confecção de blocos vazados de concreto simples para alvenaria sem função estrutural, recomenda-se que se obedeça às especificações normativas para o uso em concreto e nas argamassas ABNT (1992b). Quanto às características dos agregados para a obtenção das propriedades desejadas para os blocos de concreto, Medeiros \& Sabatinni (1993) alertam que elas podem interferir na aderência com a pasta de cimento, alterando a homogeneidade e a resistência do concreto constituinte. A cura é outro aspecto importante que interfere nas características finais do bloco de concreto. Segundo Mehta $\&$ Monteiro (1994), o termo cura do concreto trata dos procedimentos destinados a promover a hidratação do cimento, consistindo do controle de tempo, temperatura e condições de umidade imediatamente à sua colocação nas formas. As condições de cura do concreto podem interferir positiva ou negativamente, nas suas propriedades físico-mecânicas.

No intuito de contribuir com o desenvolvimento tecnológico dos processos construtivos de silos circulares verticais de alvenaria não armada e visando preencher algumas lacunas quanto à sua produção e comportamento estrutural objetivou-se, nesta pesquisa, avaliar a técnica construtiva e o desempenho mecânico de blocos de concreto. Utilizou-se, para tanto, a análise de fatores como moldagem, desmoldagem, traço e tipo de cura, além da determinação de sua resistência mecânica à compressão e ao cisalhamento.

\section{MATERIAL E MÉTODOS}

Os materiais utilizados na confecção dos blocos em estudo foram: agregado miúdo (areia lavada) proveniente do leito do Rio Paraíba; cimento Portland CP II-Z-32 e água do abastecimento da cidade de Campina Grande, Paraíba. Para caracterização do agregado miúdo se realizaram ensaios de determinação da massa específica aparente (ABNT, 1982) e determinação da composição granulometria e o módulo de finura (ABNT, 1987).

A argamassa de assentamento foi preparada manualmente utilizando-se uma superfície plana impermeável, em que os 
materiais foram misturados a seco, até se obter uma mistura uniforme; em seguida se adicionou água até a mistura se tornar homogênea. Os materiais utilizados foram: cimento, areia, massame (material argilo-arenoso) e água, no traço de 1:1,2:0,8 (cimento: areia: massame).

A proposta geométrica dos blocos foi estabelecida como sendo com dimensões de 100 × 210 × 20 mm (altura x largura $\mathrm{x}$ espessura) e um encaixe lateral para o assentamento de 10 mm (Figura 1); esses valores são semelhantes ao padrão utilizado em blocos de concreto empregados na construção civil. Como o objetivo é propor blocos de concreto para serem utilizados em silos cilíndricos verticais sem a utilização de vigas circulares (viga anel) e colunas, idealizou-se um bloco cujas faces laterais formassem um ângulo de $12^{\circ}$ em relação ao centro do silo, de tal forma que, após o assentamento de 30 unidades, se forma o ângulo de $360^{\circ}$ complementando, portanto, exatamente o perímetro.
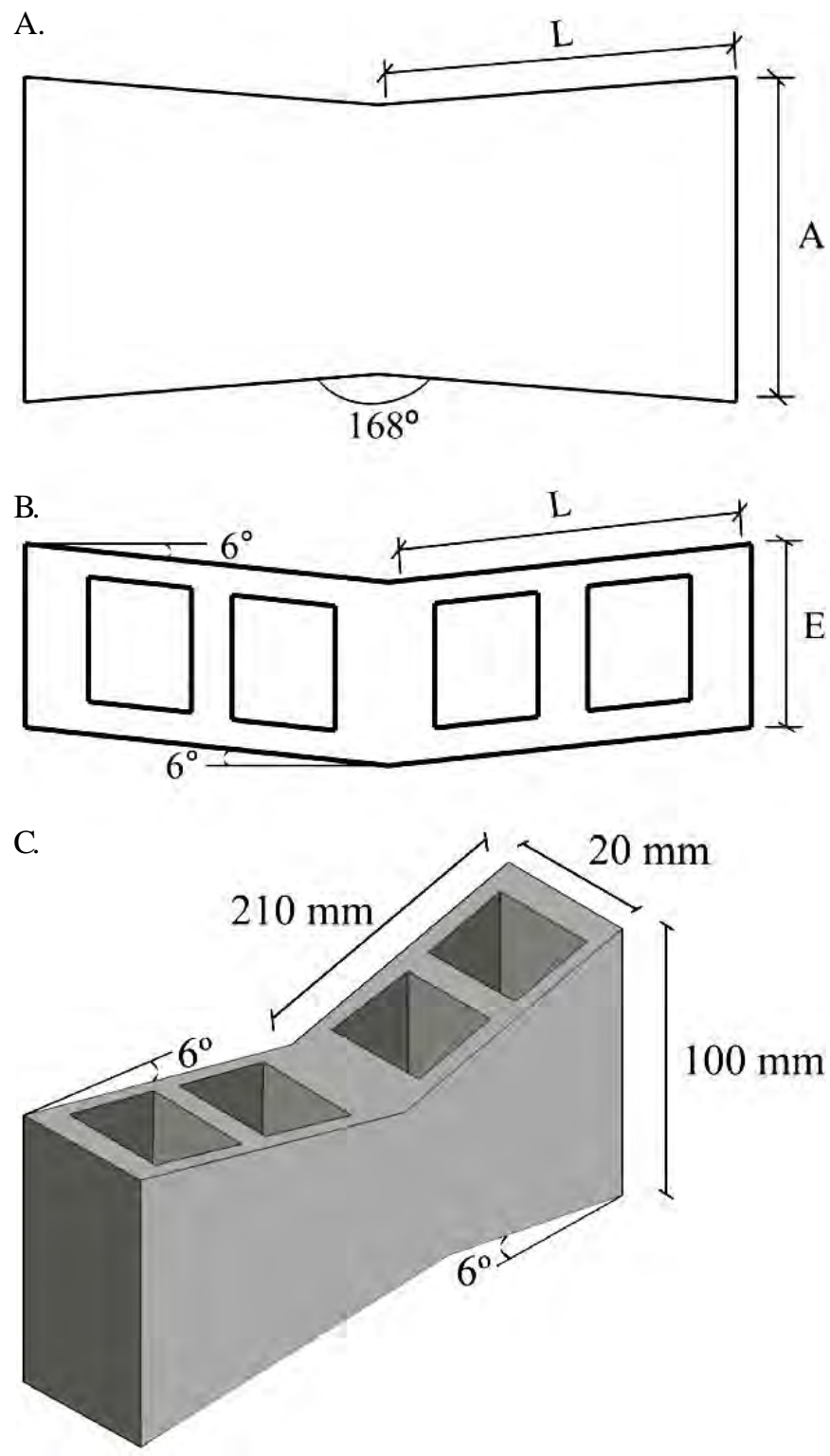

Figura 1. Geometria proposta para o bloco de concreto. (A) vista frontal, (B) vista superior, e (C) vista em perspectiva
Adotaram-se, para confecção dos blocos, os traços 1:3, 1:4 e 1:6 em volumes, transformando-os para traços em massa. Como o bloco em estudo apresentava ângulo em suas arestas, foi preciso desenvolver uma base de mesma inclinação para o desmolde. Os blocos foram moldados e, logo em seguida, desmoldados cuidadosamente, de forma a evitar deformações; após este processo os blocos ficaram $24 \mathrm{~h}$ sob cobertura plástica, procedimento que está de acordo com o recomendado pela ABNT (1994) para ensaios de corpos-deprova.

Realizaram-se dois tipos de cura para os blocos: cura ao ar livre à sombra e cura submersa, com a finalidade de se avaliar melhor o desempenho do bloco nos dois processos; para o primeiro tipo, os blocos foram colocados em local coberto e regados em intervalos de $4 \mathrm{~h}$, enquanto na cura submersa eles eram imersos em água. Para os dois tipos de cura os blocos foram submetidos a testes de resistência, aos 7, 21 e 28 dias.

A metodologia para determinar o teor de umidade e absorção dos blocos obedeceu às recomendações da ABNT (1991), por melhor representar as condições reais de uso.

A resistência á compressão simples foi definida diretamente nos blocos, aos 7, 21 e 28 dias de idade de cura, segundo o procedimento descrito pela ABNT (1992c). Durante a realização dos ensaios bases de madeira foram utilizadas sobre e sob o bloco de concreto, com a finalidade de regularizar a superfície de aplicação de carga. Entre as bases de madeira e o bloco se pôs uma lâmina de borracha enquanto no topo e na base se puseram placas rígidas de aço para melhor distribuição da carga aplicada.

O ensaio de resistência ao cisalhamento foi realizado nos blocos com os três traços combinados e os dois tipos de cura estudados em três repetições. A metodologia utilizada foi adaptada à proposta por Safarian \& Harris (1985), que consiste da moldagem do "prisma", o qual se compõe de três blocos, em que se aplica uma força de compressão equivalente à força de tração circunferencial atuante na parede do silo, além de uma protensão, que simula a pressão de atrito mais peso próprio da parede (Figura 2). Para este ensaio se utilizou uma máquina de

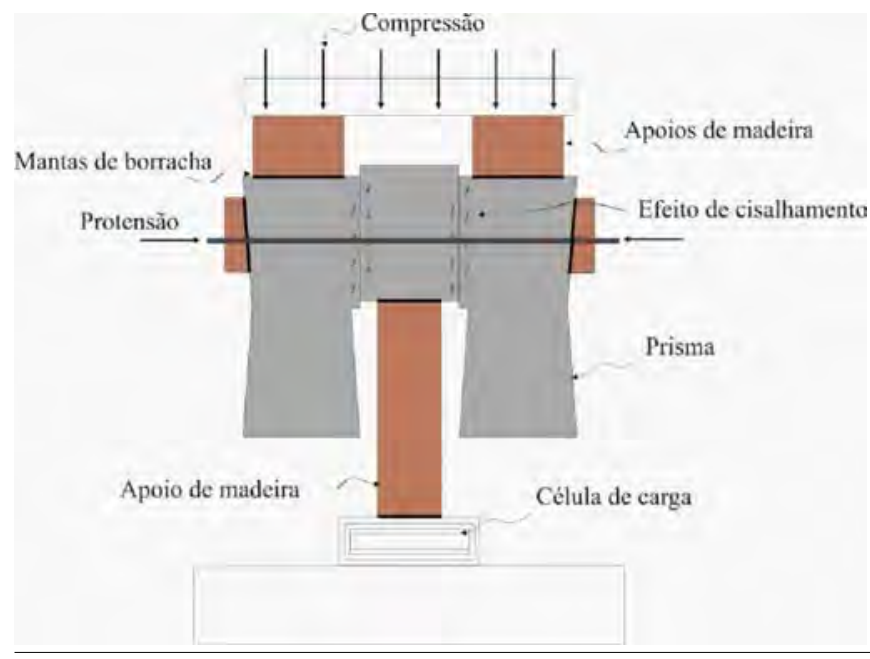

Figura 2. Esquema do ensaio de cisalhamento 
compressão com capacidade de $100 \mathrm{kN}$ e, para a leitura das cargas, foram utilizadas duas células de carga com capacidade de $20 \mathrm{kN}$ conectadas a um sistema de aquisição de dados LINX 2160.

Adotou-se, para os ensaios de compressão, um arranjo fatorial $2 \times 3 \times 3$ (dois tipos de cura com três idades de rompimento e três traços) com seis repetições. Os tratamentos se constituíram da combinação dos níveis desses três fatores, totalizando 18 tratamentos (Tabela 1).

Tabela 1. Esquema fatorial dos tratamentos experimentais utilizados nos ensaios de compressão, sendo dois tipos de cura com três idades de rompimento e três traços dos blocos de concreto

\begin{tabular}{cccc}
\hline Tratamento & Cura & Tempo (dias) & Traço* \\
T01 & Submerso & 07 & $1: 3$ \\
T02 & Submerso & 21 & $1: 4$ \\
T03 & Submerso & 28 & 16 \\
T04 & Submerso & 07 & $1: 3$ \\
T05 & Submerso & 21 & $1: 4$ \\
T06 & Submerso & 28 & 16 \\
T07 & Submerso & 07 & $1: 3$ \\
T08 & Submerso & 21 & $1: 4$ \\
T09 & Submerso & 28 & 16 \\
T10 & À sombra & 07 & $1: 3$ \\
T11 & À sombra & 21 & $1: 4$ \\
T12 & À sombra & 28 & 16 \\
T13 & A sombra & 07 & $1: 3$ \\
T14 & À sombra & 21 & $1: 4$ \\
T15 & À sombra & 28 & 16 \\
T16 & À sombra & 07 & $1: 3$ \\
T17 & À sombra & 21 & $1: 4$ \\
T18 & À sombra & 28 & 16 \\
\hline
\end{tabular}

* Cimento:Areia

Para os testes de cisalhamento considerou-se um arranjo fatorial $2 \times 3$ (dois tipos de cura com três traços) com nove repetições (Tabela 2 ).

Realizou-se, para interpretação dos resultados, uma análise de variância pelo teste "F" e comparação das médias pelo teste Tukey, utilizando-se o programa estatístico Assistat 7.0.

\section{RESULTADOS E DISCUSSÃO}

\section{Caracterização da areia}

As principais propriedades da areia utilizada na produção dos blocos e na argamassa de assentamento estão apresentadas na Tabela 3.

Os dados e as curvas obtidos nos ensaios de composição granulométrica da areia utilizada na produção dos blocos e na argamassa de assentamento estão plotados na Figura 3. De acordo com a análise granulométrica esses agregados foram classificados como areia média e fina, respectivamente, conforme a especificação da ABNT (1983).
Tabela 2. Esquema fatorial dos tratamentos experimentais utilizados nos ensaios de cisalhamento, sendo dois tipos de cura e três traços dos blocos de concreto

\begin{tabular}{ccc}
\hline Tratamento & Cura & Traço* \\
Ta & Submerso & $1: 3$ \\
Tb & À sombra & $1: 4$ \\
Tc & Submerso & $1: 6$ \\
Td & À sombra & $1: 3$ \\
Te & Submerso & $1: 4$ \\
Tf & À sombra & $1: 6$ \\
\hline
\end{tabular}

* Cimento:Areia

Tabela 3. Propriedades físicas da areia utilizada no experimento

\begin{tabular}{ccc}
\hline Propriedade & Blocos de concreto & Assentamento \\
Massa unitária em estado solto $\left(\mathrm{kg} \mathrm{m}^{-3}\right)$ & 1483 & 1460 \\
Dimensão máxima $(\mathrm{mm})$ & 2,00 & 2,40 \\
Módulo de finura & 2,94 & 2,24 \\
\hline
\end{tabular}

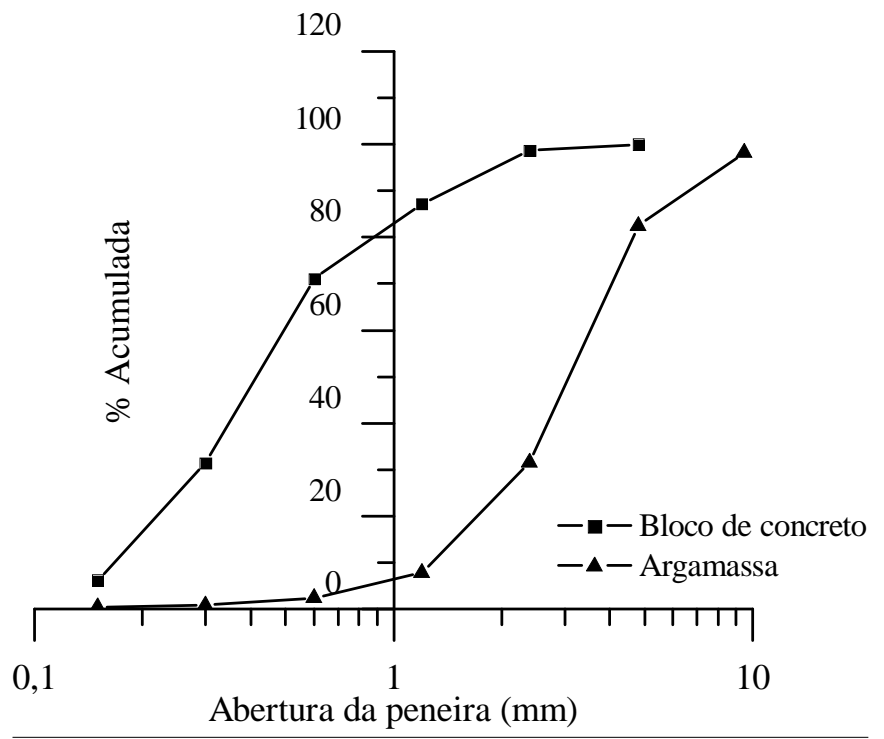

Figura 3. Curva da granulometria da areia utilizada

\section{Confecção da argamassa}

Como a principal meta deste trabalho foi propor a confecção de blocos de concreto para construção de silos de forma economicamente viável em propriedades rurais, optou-se por argamassas com traços que oferecessem facilidade de moldagem, para que os blocos pudessem ser confeccionados de forma manual. Os blocos confeccionados no traço 1:3 apresentaram defeitos em suas arestas durante a desmoldagem nos traços 1:4 e 1:6 os blocos não indicaram qualquer fissuras, sendo o traço 1:6 aquele que proporcionou melhor trabalhabilidade e acabamento.

\section{Absorção e teor de umidade por imersão}

Pela Figura 4a foi possível observar tendência de aumento da absorção a medida em que se reduziu o teor de cimento do traço, o que pode estar relacionado ao volume de vazios presentes nos traços com maior teor de areia. Para o traço 1:6, os valores de absorção foram iguais para os dois tipos de cura, á sombra e submersa. Conforme a ABNT (1992b), a 
A.

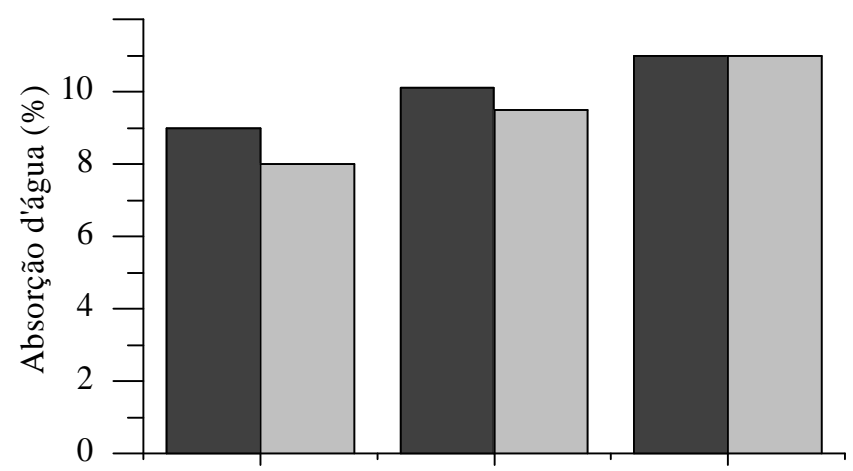

B.

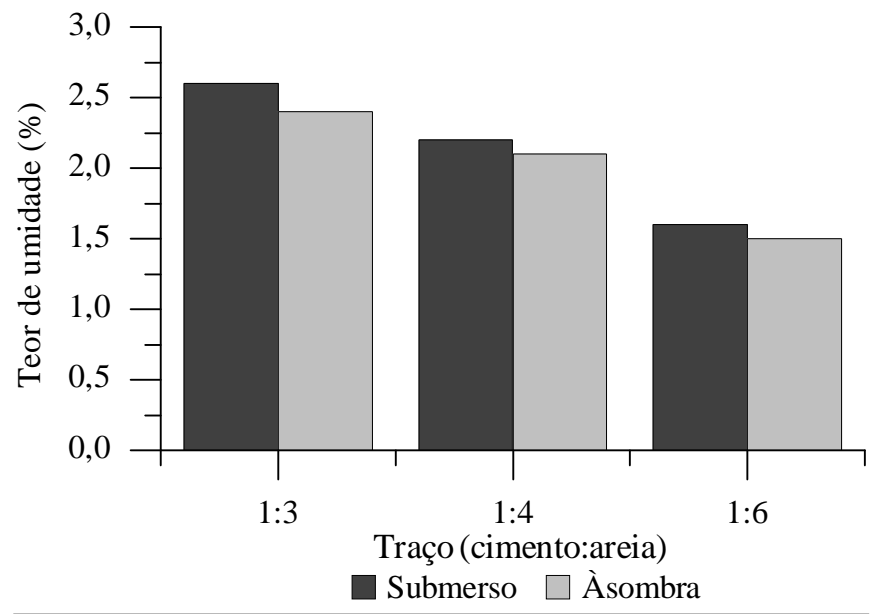

Figura 4. Absorção de água dos blocos de concreto (A), Teor de umidade dos blocos de concreto(B)

qual recomenda que a média de absorção deva ser $\leq 10 \%$ e o valor individual $\leq 15 \%$, observa-se que os traços 1:3 e 1:4 para os dois tipos de cura atendem às exigências normativas enquanto o traço 1:6 excedeu o limite estabelecido.

Vê-se, na Figura 4B, que tanto o traço quanto o tipo de cura influenciaram na variação da umidade, obtendo-se os maiores valores para os blocos moldados com traço 1:3, cujo resultado demonstra a influência do teor de cimento com relação à retenção de água no traço e a intensidade das reações químicas durante a cura. Quando se comparam os valores obtidos entre os traços, observa-se redução máxima de $1 \%$ no teor de umidade para blocos com traço 1:6; quanto à cura, nota-se, ainda, que os blocos submersos apresentaram maiores valores de umidade comparados com aqueles submetidos à cura ao ar livre, independente do traço utilizado, e que este resultado também pode estar relacionado com as condições das reações químicas.

\section{Resistência á compressão}

Pela análise do efeito do traço e da cura nos blocos de concreto constatou-se por meio, através do teste "F", a ocorrência de diferença significativa na resistência á compressão, para os fatores cura, traço e idade, a nível de $1 \%$ de probabilidade, e para as interações cura $\mathrm{x}$ traço e traço $\mathrm{x}$ idade; no entanto, para a interação cura $\mathrm{x}$ idade não houve diferença significativa e, ainda, que a resistência a compressão dos blocos submetidos a cura submersa, foi maior com relação ao tratamento ao ar livre, conforme resultados do teste de comparação de médias para o fator cura (Tabela 4). Quando da comparação das médias para o fator traço observou-se que o traço 1:3 apresentou as maiores resistências á compressão, em comparação com os traços 1:4 e 1:6.

Apresentam-se, na Figura 5, a resistência á compressão para cada um dos traços adotados em cada tipo de cura, e a tendência no tempo de cura. Tem-se, pela Figura 5A, um pequeno incremento na resistência á compressão dos blocos de concreto submetidos a cura submersa, em relação à cura ao ar livre e, ainda, que a resistência a compressão aumentou

Tabela 4. Comparação de médias dos resultados de resistência a compressão $(\mathrm{MPa})$, para blocos de concreto com cura submersa e ao ar livre, e traços 1:3, 1:4 e 1:6 (cimento:areia)

\begin{tabular}{cccc}
\hline \multirow{2}{*}{ Cura } & \multicolumn{3}{c}{ Traço } \\
\cline { 2 - 4 } Submersa & $\mathbf{1 : 3}$ & $\mathbf{1 : 4}$ & $\mathbf{1 : 6}$ \\
Ao ar livre & $2,6778 \mathrm{aA}$ & $1,9239 \mathrm{aB}$ & $1,0667 \mathrm{aC}$ \\
\hline
\end{tabular}

DMS nas colunas, letras minúsculas e nas linhas letras maiúsculas

A.

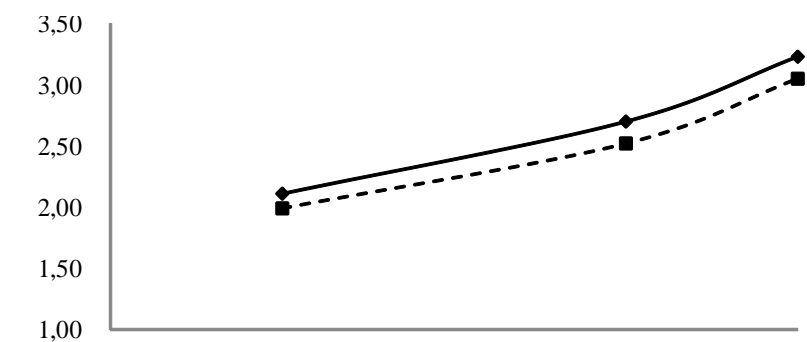

B.

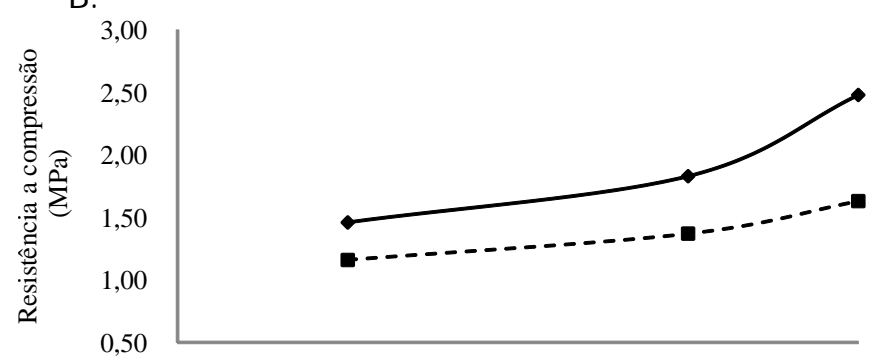

C.

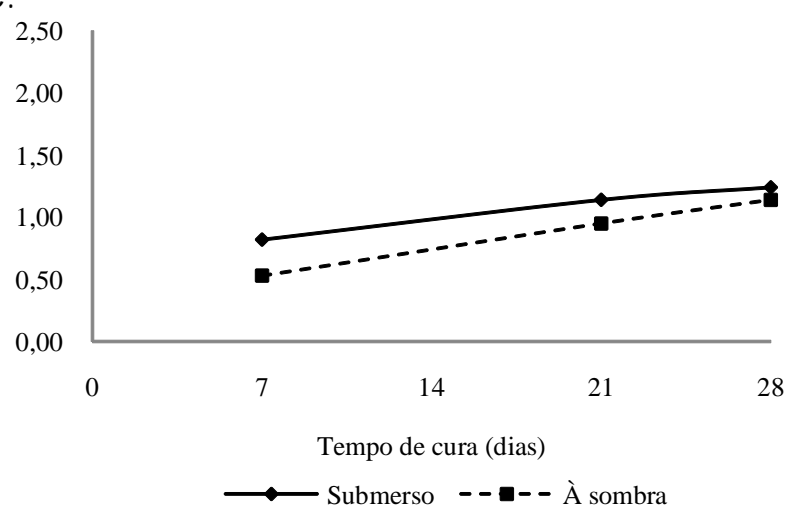

Figura 5. Resistência média a compressão do bloco de concreto nos traços: 1:3 (cimento:areia) (A), 1:4 (B) e 1:6 (C) 
com o tempo, nos dois tipos de cura, enquanto se observa, na Figura 5B, que a resistência á compressão dos blocos de concreto foi influenciada pelo tipo de cura e que, aos 28 dias, a resistência á compressão dos blocos submetidos a cura por submersão foi acrescida em $34 \%$ em relação a cura ao ar livre; na Figura 5C, se nota que a resistência á compressão teve acréscimo em função do tempo de cura nos dois tipos estudados e o maior incremento ocorreu até os 21 dias o que, em razão da baixa concentração de cimento, pode estar relacionado a reações químicas insuficientes. A superioridade dos valores de resistência á compressão na cura submersa demonstra a eficiência desse tipo de cura na hidratação do cimento; além disso, pode-se evidenciar a perda da resistência á compressão pela influência do traço, determinada pela redução da quantidade de cimento, o que fica bastante evidente na análise dos resultados do traço 1:6.

Os blocos confeccionados com traços 1:3 e submetidos aos dois tipos de cura, e aqueles com traço 1:4 sob cura submersa, atingiram resistência á compressão igual ou superior à recomendada pela ABNT (1992b); quanto aos blocos de concreto com traço 1:4 e com cura ao ar livre, e aqueles de traço 1:6 submetidos aos dois tipos de cura, esses não atingiram a resistência exigida pela ABNT (1992a); no entanto, obtiveram resistência superior à recomendada para blocos cerâmi$\cos$ (ABNT, 1992).

Ao analisar o comportamento das paredes de alvenaria produzidas com blocos vazados de concreto confeccionados com diferentes argamassas de assentamento, resistência característica e tamanhos, Medeiros \& Sabatinni (1993) observaram que os blocos com menor resistência compressão, 8,4 $\mathrm{MPa}$, apresentaram incremento de $8 \%$ na resistência da parede e nos blocos de maior resistência, 14,9 MPa, este acréscimo foi de $31 \%$. Fonseca (2002), ao caracterizar blocos de concreto de tamanhos diferenciados utilizados na confecção de paredes de alvenaria, constatou que a resistência média a compressão da área bruta dos blocos inteiros (140 x 190 x $390 \mathrm{~mm}$ ) e de meio bloco (140 x 190 x 190 mm), apresentou resistência característica á compressão, de 8,5 e 9,5 MPa respectivamente, aos 28 dias de idade.

\section{Resistência ao cisalhamento}

Em geral, em blocos de concreto destinados a alvenaria sem fim estrutural, a resistência ao cisalhamento não é a principal propriedade mecânica analisada mas, em razão da geometria e da finalidade dos blocos em estudo (construção de silos cilíndricos em fazendas), o conhecimento da resistência ao cisalhamento passa a ser primordial, pois a pressão horizontal, associada à ação do produto armazenado, tende a provocar uma força de tração circunferencial nas paredes do silo; esta, por sua vez, submeterá os blocos a esforços cisalhantes; como sua geometria foi proposta para suportar tais esforços, justifica-se analisar detalhadamente seu comportamento em relação aos traços e aos tipos de cura.

Verificou-se diferença significativa na resistência ao cisalhamento para os fatores traço e cura, a nível de $1 \%$ de probabilidade. Para a interação cura $\mathrm{x}$ traço, observou-se diferença significativa a nível de $5 \%$ de probabilidade. A comparação das médias (Tabela 5), para o fator cura, mostrou
Tabela 5. Comparação de médias dos resultados de resistência ao cisalhamento $(\mathrm{MPa})$, para blocos de concreto com cura submersa e ao ar livre, e traços 1:3, 1:4 e 1:6 (cimento:areia)

\begin{tabular}{cccc}
\hline \multirow{2}{*}{ Cura } & \multicolumn{4}{c}{ Traço } \\
\cline { 2 - 4 } Submersa & $\mathbf{1 : 3}$ & $\mathbf{1 : 4}$ & $\mathbf{1 6}$ \\
Ao ar livre & $0,5844 \mathrm{aA}$ & $0,5267 \mathrm{aB}$ & $0,4556 \mathrm{aC}$ \\
\hline
\end{tabular}

DMS nas colunas, letras minúsculas e nas linhas letras maiúsculas

que o tratamento submerso foi superior ao tratamento ao ar livre, o qual difere significativamente a nível de $1 \%$ de probabilidade pelo teste de Tukey. Para o fator traço, o traço de 1:3 obteve resistência ao cisalhamento superior à dos demais e, para as interações, a cura submersa com o traço de 1:3 foi superior à das demais combinações, diferindo significativamente a nível de $5 \%$ de probabilidade pelo teste de Tukey.

A Figura 6 indica que os blocos de concreto moldados com traço 1:3 submetidos a cura submersa, tiveram acréscimo na resistência ao cisalhamento de $18 \%$ em relação à cura ao ar livre, sendo este mesmo comportamento observado nos blocos de concreto moldados com traço $1: 4$, os quais apresentaram resistência ao cisalhamento $17 \%$ maior que aqueles submetidos à cura ao ar livre. Quanto aos blocos de concreto moldados com traço 1:6, o acréscimo da resistência ao cisalhamento foi de $21 \%$ para aqueles submetidos a cura submersa.

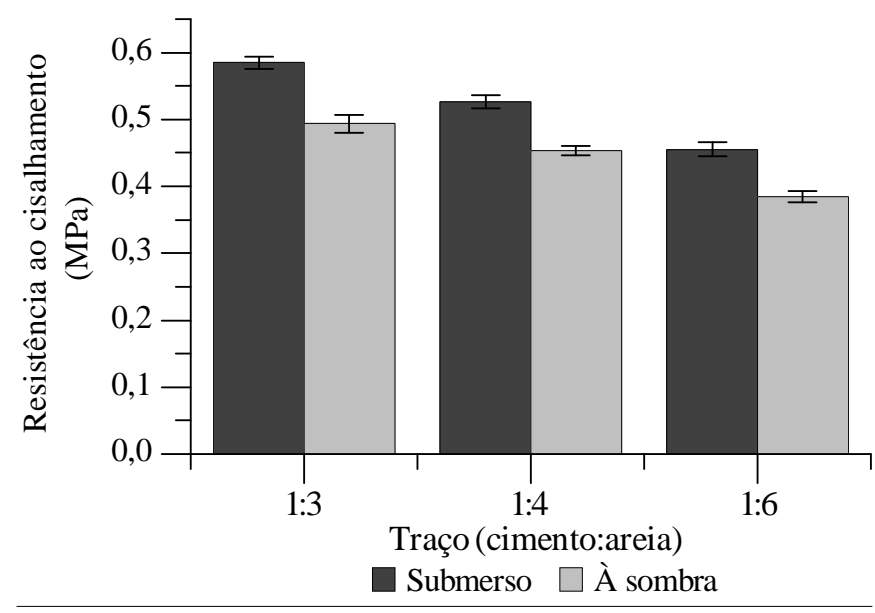

Figura 6. Resistência média ao cisalhamento dos blocos nos traços estudados aos 28 dias de cura

Para comparar as resistências á compressão e ao cisalhamento dos blocos em estudo com os possíveis esforços atuantes em silos cilíndricos, para os quais se destinam os blocos com a geometria proposta, adotou-se a norma ISO 11697 (1995), para o cálculo das pressões, considerando-se o milho o produto a ser armazenado. Observa-se, na Figura 7A, a distribuição da pressão de atrito na parede de silo cilíndrico com $4 \mathrm{~m}$ de altura e relação altura/ diâmetro igual a 1 .

A pressão máxima de atrito na parede corresponde a 4,8 $\mathrm{kPa}$. A pressão associada ao peso próprio dos blocos é igual a 45,5 kPa e, conseqüentemente, a pressão total é igual a 50,3 
A. Pressão do produto com a parede $(\mathrm{kPa})$

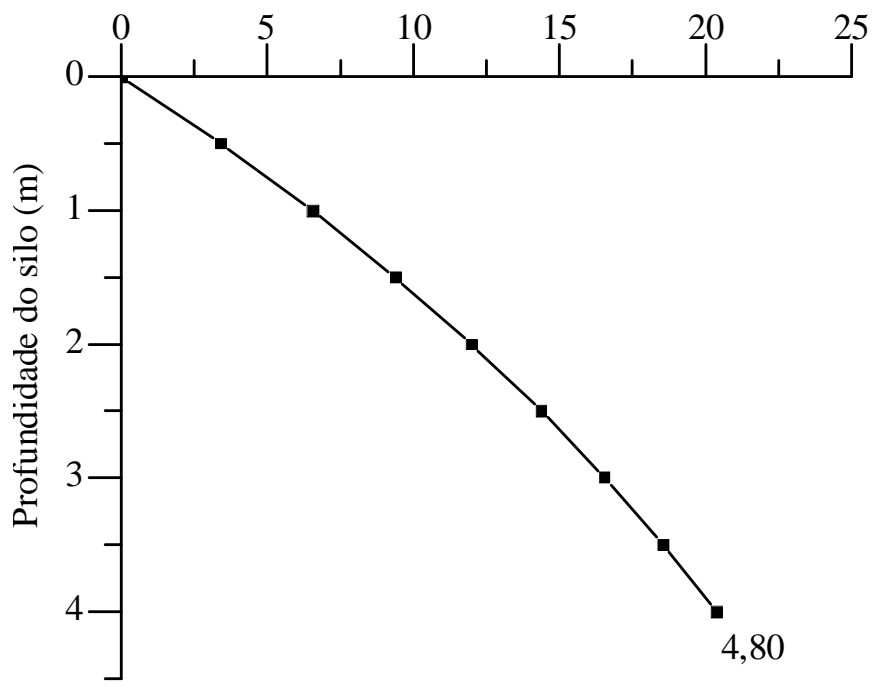

B.

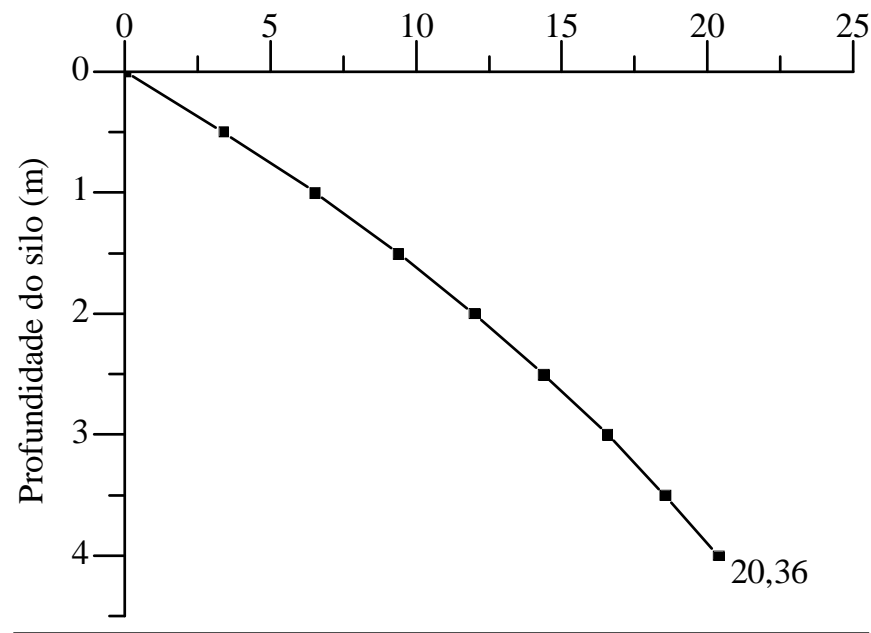

Figura 7. Distribuição da pressão de atrito do produto com a parede do silo (A) e Distribuição da pressão de atrito horizontal de descarregamento do silo (B)

$\mathrm{kPa}$; portanto, a resistência á compressão requerida no ponto crítico do silo de acordo com as especificações citadas, é bem inferior à obtida nos blocos de concreto estudados. Para o cálculo do esforço de tração circunferencial na parede dos silos, em razão do produto armazenado, é necessário determinar a pressão horizontal máxima.

Observa-se, na Figura 7B que a profundidade $\left(\mathrm{h}_{\mathrm{i}}\right)$, tem pressão horizontal correspondente $\left(\mathrm{P}_{\mathrm{hi}}\right)$ que provocará um esforço de tração $\left(\mathrm{T}_{\mathrm{i}}\right)$; desta forma, a pressão horizontal máxima atuará na profundidade igual a 4 m correspondendo a $20,36 \mathrm{kPa}$ e resultará em esforço de tração igual a 8,14 $\mathrm{kN}$. Tal valor de tração corresponde a uma tensão de tração de $407 \mathrm{kPa}$; então, com exceção do traço 1:6 com cura ao ar livre na sombra, todos possuem resistência ao cisalhamento superior ao esforço de tração que ocorreria na parede de um silo com $4 \mathrm{~m}$ de altura e $4 \mathrm{~m}$ de diâmetro; portanto, todos os traços estudados, cura e forma geométrica de blocos, podem ser utilizados na construção de silos cilíndricos com diâmetro de $4 \mathrm{~m}$ e relação altura/diâmetro até 1 .

\section{CONCLUSÕES}

1. Os blocos de concreto com traços 1:3 e 1:4 apresentaram baixa absorção, portanto podem ser utilizados na construção de silos cilíndricos verticais, sem o risco de provocar danos aos produtos devido à migração de umidade.

2. Como a resistência á compressão em todos os traços e cura foi superior aos possíveis esforços de compressão que atuaram nas paredes dos silos com as mesmas dimensões aplicadas neste estudo.

3. Os testes de resistência ao cisalhamento evidenciaram que são adequadas para suportar os esforços cisalhantes em paredes de silo cilíndrico com altura e diâmetro iguais às simuladas nos cálculos.

\section{LITERATURA CITADA}

ABNT - Associação Brasileira de Normas Técnicas. NBR 7251. Determinação da massa unitária. Rio de Janeiro: ABNT, 1982. 3p.

ABNT - Associação Brasileira de Normas Técnicas. NBR 7211. Agregados para concreto. Rio de Janeiro: ABNT, 1983. 9p.

ABNT - Associação Brasileira de Normas Técnicas. NBR 7217. Agregados. Determinação da composição granulométrica. Rio de Janeiro: ABNT, 1987. 2p.

ABNT - Associação Brasileira de Normas Técnicas. MB 3459. Blocos vazados de concreto simples para alvenaria - Determinação da absorção de água, do teor de umidade e da área liquida. Rio de Janeiro: ABNT, 1991. 3p.

ABNT - Associação Brasileira de Normas Técnicas. NBR 7171. Bloco cerâmico para alvenaria. Rio de Janeiro: ABNT, 1992a. 4p.

ABNT - Associação Brasileira de Normas Técnicas. NBR 7173. Blocos vazados de concreto simples para alvenaria sem função estrutural. Rio de Janeiro: ABNT, 1992b. 3p.

ABNT - Associação Brasileira de Normas Técnicas. NBR 7184. Blocos vazados de concreto simples para alvenaria sem função estrutural - Determinação da resistência à compressão. Rio de Janeiro: ABNT, 1992c. 2p

ABNT - Associação Brasileira de Normas Técnicas. NBR 5738. Moldagem e cura de corpo-de-prova cilíndricos ou prismáticos de concreto. Rio de Janeiro: ABNT, 1994. 9p.

Buttler, A. M.; Corrêa, M. R. S. Desenvolvimento de unidades de alvenaria estrutural produzidas com agregados reciclados de concreto. Cadernos de Engenharia de Estruturas, v.8, n.32, p. 9-12, 2006.

Diniz, M. J.; Nascimento, J. W. B. do. Análise de pressões em silo vertical de alvenaria de tijolos. Revista Brasileira de Engenharia Agrícola e Ambiental, v.10, n.1, p. 212-219, 2006.

Fonseca, F. B. Desempenho estrutural de paredes de alvenaria de blocos de concreto de agregados reciclados de rejeitos de construção e demolição. São Carlos: USP, 2002. 167p. Dissertação Mestrado

ISO - 11697. Bases for design of structures Loads due to bulk materials. Switzerland: International Classification for Standards, 1995. 15p. 
Lordsleem Júnior, A. C.; Póvoas, Y. V.; Sousa, R. V. R. de.; Silva, C. F. C. da. Blocos de concreto para vedação: estudo da conformidade através de ensaios laboratoriais. In: Encontro Nacional de Engenharia de Produção. A integração de cadeias produtivas com a abordagem da manufatura sustentável, 28, 2008, Rio de Janeiro. Anais... Rio de Janeiro: APEBRO, 2008. CD Rom

Medeiros, J. S.; Sabatinni, F. H. Alvenaria estrutural não armada de blocos de concreto: produção de componentes e parâmetros de projeto. Boletim Técnico da Escola Politécnica da USP. São Paulo: Escola Politécnica da USP, 1993, 24p.

Mehta, P. K.; Monteiro, P. J. M. Concreto: Estrutura, propriedades e materiais. São Paulo: Pini, 1994. 616p.

Safarian, S. S.; Harris, E. C. Design and construction of silos and bunkers. New York: van Nostrand Reinhold Company Inc., 1985. 468p.
Silva, A. C. S.; Alves, V. R.; Mendes, L. C. Comportamento à compressão de paredes em alvenaria estrutural. In: Semana de Engenharia da UFF, 7, 2005, Niterói. Anais... Niterói: UFF, 2005. CD Rom

Sousa, J. G. G. Contribuição ao estudo da relação entre propriedades e proporcionamento de blocos de concreto - Aplicação ao uso de entulho como agregado reciclado. Brasília: UNB, 2001. 120p. Dissertação Mestrado

Vieira, G. L.; Dal Molin, C. C. Contribuição ao estudo e análise de viabilidade da utilização de concretos com agregados Reciclados de resíduos de construção e demolição. In: Seminário de Patologias de Edificações. Novos Materiais e Tecnologias Emergentes, 2, 2004, Porto Alegre. Anais.....Porto Alegre: UFRGS, 2004. CD Rom. 